\title{
Stability of busulfan solutions in polypropylene syringes and infusion bags as determined with an original assay
}

Nicolas Guichard, M.Sc. (Ph.D. student), Geneva University Hospitals, Geneva, Switzerland, and School of Pharmaceutical Sciences, University of Geneva, Geneva, Switzerland.

Pascal Bonnabry, Ph.D., Geneva University Hospitals, Geneva, Switzerland, and School of Pharmaceutical Sciences, University of Geneva, Geneva, Switzerland.

Serge Rudaz, Ph.D., School of Pharmaceutical Sciences, University of Geneva, Geneva, Switzerland.

Sandrine Fleury-Souverain, Ph.D., Geneva University Hospitals, Geneva, Switzerland.
Address correspondence to Mr. Guichard (nicolas.guichard@hcuge.ch).

Copyright ( 2017 , American Society of Health-System Pharmacists, Inc. All rights reserved. 1079-2082/17/1102-1887.

DOI 10.2146/ajhp160516
Purpose. The stability of busulfan solution in $0.9 \%$ sodium chloride and stored in polypropylene syringes or infusion bags was evaluated.

Methods. Busulfan solutions $(0.54 \mathrm{mg} / \mathrm{mL})$ were prepared and transferred to $50-\mathrm{mL}$ polypropylene syringes and $100-$ and $500-\mathrm{mL}$ polypropylene infusion bags and stored at $2-8$ and $23-27^{\circ} \mathrm{C}$. Chemical stability was measured using a stability-indicating, ultrahigh performance liquid chromatography coupled to mass spectrometry method. The stability of busulfan was assessed by measuring the percentage of the initial concentration remaining at the end of each time point of analysis. The initial busulfan concentration was defined as $100 \%$. Stability was defined as retention of at least $90 \%$ of the initial busulfan concentration. A visual inspection of the samples for particulate matter, clarity, and color without instrumentation of magnification was conducted at each time point of analysis.

Results. The visual inspection demonstrated no influence of the storage container when busulfan infusions diluted in $0.9 \%$ sodium chloride injection were stored at $23-27^{\circ} \mathrm{C}$. No color change or precipitate was observed at this temperature; however, a rapid decrease of the busulfan content in all containers stored at room temperature was observed. Busulfan in syringes was chemically stable for 12 hours, while busulfan in infusion bags $\left(100\right.$ and $500 \mathrm{~mL}$ ) was stable only for 3 hours at $23-27^{\circ} \mathrm{C}$.

Conclusion. Busulfan $0.54-\mathrm{mg} / \mathrm{mL}$ solution in $0.9 \%$ sodium chloride injection was physically and chemically stable for 30 hours when stored in $50-\mathrm{mL}$ polypropylene syringes at $2-8^{\circ} \mathrm{C}$ and protected from light.

Keywords: antineoplastic agents; busulfan; chemical precipitation; chromatography, liquid; drug stability; mass spectrometry

Am J Health-Syst Pharm. 2017; 74:1887-94
D usulfan, a bifunctional alkylating agent in the class of alkyl sulfonate antineoplastic drugs, is extensively used in myeloablative regimens before hematopoietic stem cell transplantation. ${ }^{1}$ This molecule was discovered in the early 1950s and orally administered in clinical trials for the palliative treatment of chronic myeloid leukemia. ${ }^{2}$ However, this treatment demonstrated highly variable pharmacokinetics, mainly induced by poor absorption after oral administration or presence of vomiting and variations in dietary intake, which can influence the outcome of the bone marrow transplantation. ${ }^{1,3-5}$ In order to increase the bioavailability of busulfan, an i.v. form was developed. Since busulfan has an extremely low solubility in water, the use of cosolvents was required to allow its solubilization. The i.v. form was initially commercially available as Busulfex (Otsuka) in the U.S. market as a clear, colorless concentrated solution of $6 \mathrm{mg} / \mathrm{mL}$ dissolved in $N, N$-dimethylacetamide (DMA, 33\% by volume) and poly- 
ethylene glycol 400 (PEG400, 67\% by weight). ${ }^{6}$ The same formulation was approved in Europe under the brand name Busilvex (Pierre Fabre).

Currently, busulfan is indicated in conjunction with other antineoplastic agents such as cyclophosphamide (for adults) or melphalan (for children) for conditioning before hematopoietic stem cell transplantation. Other antineoplastic agents, such as fludarabine or thiotepa, are also used with busulfan. ${ }^{7,8}$

According to the summary of product characteristics for parenteral busulfan, the concentrate must be diluted before administration in $0.9 \%$ sodium chloride injection or $5 \%$ dextrose injection to a final concentration of $0.54 \mathrm{mg} / \mathrm{mL} .^{9}$ The solution is stated to be stable for 8 hours at room temperature when the product is diluted in $5 \%$ dextrose injection. When the dilution is performed with $0.9 \%$ sodium chloride injection, the solution is stable for 12 hours under refrigeration $\left(2-8{ }^{\circ} \mathrm{C}\right)$ or 3 hours at room temperature.

Busulfan is usually administered over 2 hours every 6 hours for 4 consecutive days, for a total of 16 doses. The limited stability of this product induces organizational problems for cytotoxic preparation units in hospital pharmacies.

A few studies have been conducted to investigate how to increase the stability of diluted busulfan solutions. Busulfan is known to undergo rapid hydrolysis degradation at room temperature, yielding tetrahydrofuran and methanesulfonic acid..$^{10,11}$ Nevertheless, a U.S. study conducted in 1996 found that busulfan was chemically and physically stable at room temperature when reconstituted in $0.9 \%$ sodium chloride injection or $5 \%$ dextrose injection and stored in polyvinyl chloride (PVC) or polyolefin bags for 8 hours. ${ }^{12} \mathrm{~A}$ more recent German study highlighted the physical instability of busulfan stored at low temperatures $\left(2-8{ }^{\circ} \mathrm{C}\right)$ due to precipitation and concluded that busulfan diluted in $0.9 \%$ sodium chlo-

\section{KEY POINTS}

- The stability-indicating method used was more sensitive, more specific, and faster than conventional high-performance liquid chromatography with ultraviolet light, with prior derivatization step methods used for already published stability studies.

- The physical stability of diluted busulfan solutions was very labile and strongly dependent on container type.

- Busulfan 0.54-mg/mL solution in $0.9 \%$ sodium chloride injection was physically and chemically stable for 30 hours when stored in 50-mL polypropylene syringes at $2-8^{\circ} \mathrm{C}$ and protected from light.

ride injection and stored at $10-15{ }^{\circ} \mathrm{C}$ is stable for up to 48 hours. ${ }^{13}$ That intermediate temperature was chosen to strike a balance between busulfan hydrolysis and the occurrence of precipitation. In 2013, a French group reported on the stability of busulfan in polypropylene syringes, PVC bags, and glass bottles at 3 different temperatures $\left(5,14\right.$, and $\left.20^{\circ} \mathrm{C}\right)$ and confirmed the precipitation observed by the German group when busulfan in $0.9 \%$ sodium chloride injection was stored at a low temperature. ${ }^{14}$ However, stability was the longest (24 hours) when diluted bisulfan was stored in polypropylene syringes at $5^{\circ} \mathrm{C}$.

Most of the busulfan stability studies were based on quantitation with high-performance liquid chromatography (HPLC) with ultraviolet (UV)-light detection. However, busulfan has no chromophore functional group, and a derivatization step before analysis is required in order to make the compound visible under UV light. Derivatization can be tedious, as it often requires a long reaction time (more than 1 hour) or heat to be achieved. Given the unstable nature of busulfan, a method with a short overall analysis time without a derivatization step seems to be more suitable for determining the stability of pharmaceutical formulations containing this molecule.

Ultra-HPLC (UHPLC) coupled to mass spectrometry (UHPLC-MS) is a sensitive, highly specific, and fast analytic technique. Moreover, no prior derivatization step is required for busulfan analysis. This technique is widely used for monitoring plasma busulfan levels and making dosage adjustments, particularly for pediatric patients. ${ }^{15-19}$ Nevertheless, to our knowledge no UHPLC-MS method has been developed for evaluating the stability of busulfan.

This study investigated the stability of busulfan diluted in $0.9 \%$ sodium chloride injection and stored in polypropylene syringes and infusion bags at $2-8$ and $23-27^{\circ} \mathrm{C}$ using UHPLC-MS.

\section{Methods}

Materials. Busulfan, a ${ }^{\mathrm{a}}\left[\mathrm{H}_{8}\right]$-busulfan ${ }^{\mathrm{b}}$ (internal standard), Busilvex ${ }^{\mathrm{c}}$ from 3 different lots (designated as lots A, B, and $\mathrm{C}$ ), syringes, ${ }^{\mathrm{d}}$ syringe caps, ${ }^{\mathrm{e}}$ and infusion bags containing $0.9 \%$ sodium chloride injection ${ }^{\mathrm{f}}$ were obtained commercially. Ultrapure water, ${ }^{\mathrm{g}}$ liquid chromatography-MS grade acetonitrile, ${ }^{\mathrm{h}}$ formic acid, ${ }^{\mathrm{i}}$ and ammonium formate ${ }^{\mathrm{j}}$ were used for mobile-phase preparation. WFI-grade water $^{\mathrm{k}}$ was used for sample dilution. Forced degradation studies were performed with sodium hydroxide, ${ }^{1}$ hydrochloric acid, ${ }^{\mathrm{m}} 30 \%$ hydrogen peroxide, ${ }^{\mathrm{n}}$ and heat $\left(80^{\circ} \mathrm{C}\right)$. $\mathrm{DMA}^{\circ}$ and PEG400 (Macrogol 400) ${ }^{\mathrm{p}}$ were used for signal enhancement/ suppression effect investigations.

Preparation of reference solutions. Busulfan reference solution for UHPLC-MS assay was prepared by dissolving $54 \mathrm{mg}$ of busulfan powder in acetonitrile using a $20-\mathrm{mL}$ volumetric flask. Because the solution was demonstrated to be stable for at least 5 days at $-20^{\circ} \mathrm{C}$, aliquots were placed in 
$500-\mu \mathrm{L}$ plastic vials and stored at -20 ${ }^{\circ} \mathrm{C}$ for the whole duration of the study.

The internal standard was prepared by dissolving $10 \mathrm{mg}$ of $\left[{ }^{2} \mathrm{H}_{8}\right]-$ busulfan in acetonitrile using a $20-\mathrm{mL}$ volumetric flask. Because the solution was demonstrated to be stable for 2 months, aliquots were placed in $500-\mu \mathrm{L}$ plastic vials and stored at -20 ${ }^{\circ} \mathrm{C}$ until use. A working solution of 10 $\mu \mathrm{g} / \mathrm{mL}$ was obtained by dilution with WFI-grade water and a $10-\mathrm{mL}$ volumetric flask. The working solution was freshly prepared for each time point of analysis.

UHPLC-MS assay method. The optimized method to assay busulfan by UHPLC-MS used an ultrafast liquid chromatograph system coupled to a mass spectrometer consisting of a high-vacuum pump; ${ }^{\mathrm{q}}$ a thermostated autosampler; a quaternary-flow solvent-delivery system; $;$ a $2.1 \times 50$ $\mathrm{mm}, 1.7-\mu \mathrm{m} \mathrm{C}_{18}$ column $^{\mathrm{t}}$ fitted with a guard column; ${ }^{\text {u }}$ a thermostatic column compartment; ; and a triple-quadrupole mass spectrometer detector. ${ }^{w}$ The column compartment was maintained at $35{ }^{\circ} \mathrm{C}$, and the sample-manager temperature was maintained at $10{ }^{\circ} \mathrm{C}$ to limit sample degradation during the run time. The injection volume was set to $2 \mu \mathrm{L}$.

The mass spectrometer was operated in positive-ion electrospray ionization mode. Electrospray settings were as follows: capillary voltage, 3.00 $\mathrm{kV}$; cone voltage, $18 \mathrm{~V}$; and source and desolvation temperatures, 150 and $450{ }^{\circ} \mathrm{C}$, respectively. Desolvation and cone gas flow were set to 800 and 30 $\mathrm{L} / \mathrm{hr}$, respectively. Positive ionization with selected-ion recording mode was used, and the multiplier gain was set on 1 . Busulfan and $\left[{ }^{2} \mathrm{H}_{8}\right]$-busulfan were detected as ammonium adducts at $\mathrm{m} / \mathrm{z} 264.1$ and 272.1, respectively. Peak areas of busulfan and $\left[{ }^{2} \mathrm{H}_{8}\right]-$ busulfan were analyzed, and subsequent calculation of calibration curves and quantification of busulfan were performed with MassLynx software, version 4.1 (Waters, Milford, MA).

Two mobile phases, designated $\mathrm{A}$ and $\mathrm{B}$, consisted of $5 \mathrm{mmol} / \mathrm{L}$ am- monium formate and $0.1 \%$ formic acid in water (A) and pure acetonitrile (B). Gradients were programmed as follows: $20 \%$ mobile phase B for 0.4 minutes, increased to $80 \% \mathrm{~B}$ for 0.5 minutes, and then equilibrated with $20 \%$ B for 0.8 minutes. A flow rate of $0.6 \mathrm{~mL} / \mathrm{min}$ was applied. A columnswitching valve was used to switch the liquid flow into the detector between 0.4 and 1.0 minutes after injection. Each analysis was confirmed by a second injection of the sample, with an acceptance specification lower than $1 \%$ of the difference in response. The results were reported as the average of both analyses.

Antineoplastic substances handling. All manipulations of toxic substances were executed inside a class II biological-safety cabinet with appropriate and certified personal protective equipment, including safety goggles, mask, gloves, hand sleeves, and gown. ${ }^{20}$

Method validation. The developed method was validated according to the International Conference on Harmonisation (ICH) guidelines following the recommendations of the Commission of the French Society of Pharmaceutical Science and Technology (SFSTP). ${ }^{21-23}$ The calibration curves $\left(r^{2}>0.999\right)$ were obtained for each series with conventional leastsquare linear regression using 3 concentrations $(378,540$, and $648 \mathrm{ng} / \mathrm{mL}$ ) by plotting the area ratio $\mathrm{m} / \mathrm{z}(264.1$ and 272.1 for busulfan and $\left[{ }^{2} \mathrm{H}_{8}\right]-$ busulfan, respectively) against busulfan concentrations. No weighing function was applied. Calibration samples were prepared by diluting an adequate volume of busulfan reference solution to reach concentrations of 378,540 , and $648 \mathrm{ng} / \mathrm{mL}$ using 10-mL volumetric flasks and WFI-grade water. Next, $500 \mu \mathrm{L}$ of $\left[{ }^{2} \mathrm{H}_{8}\right]$-busulfan working solution was added as internal standard to obtain a final concentration of 500 $\mathrm{ng} / \mathrm{mL}$ in the sample. Validation samples were prepared by diluting $900 \mu \mathrm{L}$ of Busilvex in $0.9 \%$ sodium chloride injection using a $10-\mathrm{mL}$ volumetric flask, yielding a final busulfan concen- tration of $0.54 \mathrm{mg} / \mathrm{mL}$. The solution was then diluted in $10-\mathrm{mL}$ volumetric flasks with WFI-grade water to final busulfan concentrations of 378,540 , and $648 \mathrm{ng} / \mathrm{mL}$. Next, $500 \mu \mathrm{L}$ of $\left[{ }^{2} \mathrm{H}_{8}\right]-$ busulfan working solution was added to each calibration sample to obtain a final concentration of $500 \mathrm{ng} / \mathrm{mL}$ in the sample. Calibration and validation samples were analyzed twice, and the average result was used to determine calculations and method validation.

The quantitative performance of the developed method was estimated using 3 separate series $(n=3)$. For each series, 6 independent calibration samples (2 for each concentration) and 12 independent validation samples (4 for each concentration) were analyzed. After establishing the calibration curves for each series, concentrations of validation samples were computed from the analytic response to obtain trueness, repeatability, and intermediate precision. Trueness, expressed as a percentage, was the ratio between theoretical and average measured values at each concentration. Repeatability and intermediate precision were expressed as the relative standard deviation (RSD) (i.e., the ratio of the intraday standard deviation [sr] and interday standard deviation [sR], respectively, to the theoretical concentrations).

As reported in Table 1, trueness and precision values were in accordance with recommendations for the analysis of pharmaceutical formulations over the tested concentration range. The RSD values (repeatability and intermediate precision) were lower than $1.3 \%$, with trueness values between $100 \%$ and $101 \%$. The accuracy profile was then obtained according to the SFSTP 2006 recommendations ( $\beta=95 \%$ ). The upper and lower tolerance limits represented the total error of the method, based on the tolerance interval (Table 1).

Forced degradation studies. Forced degradation studies were performed to provide an indication of the stability-indicating properties and specificity of the method. Inten- 
tional degradation of busulfan was attempted using hydrochloric acid (0.1, 0.5 , and $1 \mathrm{~mol} / \mathrm{L})$, sodium hydroxide $(0.1,0.5$, and $1 \mathrm{~mol} / \mathrm{L}), 30 \%$ hydrogen peroxide, and heat $\left(80{ }^{\circ} \mathrm{C}\right)$, following the ICH recommendations and methodological guidelines for stability studies of hospital pharmaceutical preparations. ${ }^{24}$ After the degradation treatments were completed, all samples were allowed to cool to room temperature, neutralized with acid or base (if needed), and prepared according to the assay procedures. Because of the high specificity of MS and the low molecular mass of already identified degradation products (tetrahydrofuran and methanesulfonic acid), there was no ambiguity on main peak product identification ( $\mathrm{m} / \mathrm{z}, 264.1)$, and no interference between busulfan and its degradation products was observed (data not shown).

Physical assessment. A visual inspection of the samples for particulate matter, clarity, and color without instrumentation of magnification was conducted at each time point of analysis.

Data analysis. The stability of busulfan was assessed by measuring the percentage of the initial concentration remaining at the end of each time point of analysis. The initial busulfan concentration was defined as $100 \%$. Stability was defined as retention of at least $90 \%$ of the initial busulfan concentration.

Sample preparation. Syringes. Three bulk solutions from 3 Busilvex lot numbers were prepared by diluting $19.73 \mathrm{~g}$ of Busilvex in $180.8 \mathrm{~g}$ of $0.9 \%$ sodium chloride injection. These

Table 1. Validation Results for Busulfan Assay ${ }^{a}$

\begin{tabular}{ccccc}
\hline \multirow{2}{*}{$\begin{array}{c}\text { Theoretical } \\
\text { Busulfan Conc. } \\
\text { (ng/mL) }\end{array}$} & Trueness & $\begin{array}{c}\text { Repeatability, } \\
\text { RSD }\end{array}$ & $\begin{array}{c}\text { Intermediate } \\
\text { Precision, RSD }\end{array}$ & $\begin{array}{c}\text { Tolerance } \\
\text { Interval }\end{array}$ \\
\cline { 2 - 5 } & 100.0 & 0.8 & 1.3 & $97.0-103.0$ \\
\hline 378 & 100.8 & 1.1 & 1.3 & $97.9-103.8$ \\
\hline 540 & 101.0 & 1.2 & 1.2 & $98.2-103.7$ \\
\hline 648 & & & \\
\hline${ }^{a}$ RSD $=$ relative standard deviation. & & &
\end{tabular}

solutions were homogenized with a magnetic stirrer for 5 minutes prior to dispensing in $1250-\mathrm{mL}$ syringes (4 for each lot number). A 300- $\mu \mathrm{L}$ sample was withdrawn in each syringe for initial busulfan quantification. For each batch, 3 syringes were stored at $2-8{ }^{\circ} \mathrm{C}$ in a regulated climatic chamber and 1 syringe was stored at room temperature $\left(23-27^{\circ} \mathrm{C}\right)$. All syringes were protected from light.

Infusion bags. Four 100-mL infusion bags were prepared for each different Busilvex lot number. From each container, $9 \mathrm{~mL}$ of $0.9 \%$ sodium chloride injection was withdrawn with a 10-mL syringe $\mathrm{e}^{\mathrm{x}}$ and a 20G needle followed by an injection of the same volume of Busilvex. The containers were then vigorously shaken prior to individual busulfan concentration determination by UHPLC-MS. For each batch, 3 containers were stored at $2-8{ }^{\circ} \mathrm{C}$ in a regulated climatic chamber and 1 container was stored at room temperature $\left(23-27^{\circ} \mathrm{C}\right)$. All containers were protected from light.

Four 500-mL infusion bags were prepared from 3 different Busilvex lot numbers ( 2 from lot $A$ and 1 each from lots B and C). From each container, 45 $\mathrm{mL}$ of $0.9 \%$ sodium chloride injection was withdrawn with a $50-\mathrm{mL}$ syringe $\mathrm{y}^{\mathrm{y}}$ and a $18 \mathrm{G}$ needle ${ }^{\mathrm{d}}$ followed by an injection of $45 \mathrm{~mL}$ of Busilvex. The containers were then vigorously shaken prior to individual quantification of busulfan by UHPLC-MS. All bags were stored at $2-8{ }^{\circ} \mathrm{C}$ in a regulated climatic chamber except 1 bag from lot A that was stored at room temperature $\left(23-27{ }^{\circ} \mathrm{C}\right)$. All containers were protected from light.
Sample analysis. At each time point of analysis, all containers were vigorously shaken and observed for physical assessment prior to withdrawal of the sample with 1-mL syringes $^{\mathrm{z}}$ and $22 \mathrm{G}$ needles. ${ }^{\text {aa }}$ The number of containers, sampling times, and volumes are summarized in Table 2 .

\section{Results and discussion}

Ion suppression or enhancement effect. A modification of the MS signal can be observed when several compounds are coeluted into the mass spectrometer. Such a phenomenon might induce an error in the quantification of the target compound. In the case of pharmaceutical formulations, particular attention should be paid to the possible coelution of excipients and target compound. For example, PEG (widely used as a solubilization agent) is known to cause strong signal suppression..$^{25}$ An assay was conducted to investigate this effect for both the excipients of Busilvex-PEG400 and DMA. Three solutions were prepared: 1 with PEG400 only, 1 with DMA only, and 1 with a mixture (2:1 ratio, weight/ weight) of these 2 products. These solutions were diluted following the standard assay procedure and injected in the UHPLC-MS system with the parameters described above. A busulfan solution (100 $\mathrm{ng} / \mathrm{mL}$ in acetonitrile) at a $50-\mu \mathrm{L} / \mathrm{min}$ flow rate was continuously injected into the mass spectrometer with a postcolumn-injection procedure. The busulfan signal recording was examined to visualize the effects of excipients on the signal. DMA did not have any influence; however, PEG400 showed numerous ion suppression zones at different retention times. Optimization of the gradient and column temperature was performed to remove overlap between ion suppression zones and busulfan retention time (data not shown).

Stability study results. The visual inspection demonstrated no influence of the storage container when busulfan infusions diluted in $0.9 \%$ sodium chloride injection were stored at $23-27^{\circ} \mathrm{C}$. No color change or 
Table 2. Experimental Conditions in Determining Stability of Busulfan $0.54 \mathrm{mg} / \mathrm{mL}$ in $0.9 \%$ Sodium Chloride Injections

\begin{tabular}{|c|c|c|c|c|}
\hline Containers & $\begin{array}{c}\text { Storage } \\
\text { Temperature, }{ }^{\circ} \mathbf{C}\end{array}$ & $\begin{array}{c}\text { No. } \\
\text { Containers }\end{array}$ & Sample Volume, $\mu \mathrm{L}$ & Sampling Times, hr \\
\hline \multirow[t]{2}{*}{ 50-mL polypropylene syringes } & $2-8$ & 9 & 300 & $\begin{array}{l}0,3,6,12,17,24,30,33,36 \\
\quad 50\end{array}$ \\
\hline & $23-27$ & 3 & 300 & $0,3,6,12,17,24,30,36,50$ \\
\hline \multirow[t]{2}{*}{$\begin{array}{l}100-m L \text { polypropylene infusion } \\
\text { bags }\end{array}$} & $2-8$ & 9 & 300 & $\begin{array}{l}0,3,6,9,12,15,19,23,28 \\
\quad 33,100\end{array}$ \\
\hline & $23-27$ & 3 & 300 & $0,3,6,9,12,15,19,23,28,31$ \\
\hline \multirow{2}{*}{$\begin{array}{l}500-m L \text { polypropylene infusion } \\
\text { bags }\end{array}$} & $2-8$ & 3 & 500 & $0,3,5,9,13,16,19,22$ \\
\hline & $23-27$ & 1 & 500 & $0,3,5,9,13,16,19,22$ \\
\hline
\end{tabular}

precipitate was observed at this temperature; however, a rapid decrease of the busulfan content in all containers stored at room temperature was observed. As shown in Table 3, busulfan in syringes was chemically stable for 12 hours; busulfan in infusion bags (100 and $500 \mathrm{~mL}$ ) was stable only for 3 hours at $23-27{ }^{\circ} \mathrm{C}$ if a $10 \%$ threshold limit was considered (Tables 4 and 5). These results were consistent with those obtained by Houot et al., ${ }^{14}$ who demonstrated the stability of busulfan for 15 hours when stored in polypropylene syringes and for 6 hours when stored in PVC infusion bags at room temperature. Moreover, Houot et al. ${ }^{14}$ found that the stability of busulfan in infusion bags stored at room temperature was shorter than expected compared with that found in the summary of product characteristics. ${ }^{9}$

At a lower temperature $\left(2-8^{\circ} \mathrm{C}\right)$ the stability of diluted busulfan solution was mainly driven by the physical assessment. Indeed, white crystals were detected on the syringes' surface after 33 hours of storage. This observation could be correlated with the quantification results obtained for the syringes stored at $2-8{ }^{\circ} \mathrm{C}$ (Table 3 ). Indeed, all the tested solutions remained above the $90 \%$ threshold limit for 30 hours ( $n=9$, RSD $<2 \%$ ). The variability in crystallization kinetics resulted in the relatively large standard deviations observed for time points after 30 hours.

Busulfan crystallization was also detected in the 100-mL infusion bags,

Table 3. Stability of Busulfan $0.54 \mathrm{mg} / \mathrm{mL}$ in $0.9 \%$ Sodium Chloride Injection Stored in 50-mL Polypropylene Syringes

\begin{tabular}{|c|c|c|}
\hline \multirow[b]{2}{*}{ Study Time, hr } & \multicolumn{2}{|c|}{$\begin{array}{l}\text { Mean } \pm \text { S.D. \% Initial Busulfan } \\
\text { Conc. Remaining at Indicated } \\
\text { Storage Temperature }\end{array}$} \\
\hline & $2-8^{\circ} \mathrm{C}^{a}$ & $23-27^{\circ} C^{b}$ \\
\hline 3 & $97.14 \pm 0.79$ & $93.60 \pm 0.42$ \\
\hline 6 & $96.41 \pm 0.47$ & $93.26 \pm 0.45$ \\
\hline 12 & $99.25 \pm 0.52$ & $98.34 \pm 3.97$ \\
\hline 17 & $96.93 \pm 0.67$ & $85.42 \pm 0.87$ \\
\hline 24 & $97.99 \pm 1.29$ & $80.18 \pm 1.53$ \\
\hline 30 & $93.93 \pm 1.52$ & $75.57 \pm 1.00$ \\
\hline 33 & $88.89 \pm 1.93$ & $N A^{c}$ \\
\hline 36 & $88.93 \pm 3.35$ & $68.11 \pm 1.30$ \\
\hline 50 & $78.91 \pm 11.39$ & $68.04 \pm 0.17$ \\
\hline \multicolumn{3}{|c|}{ 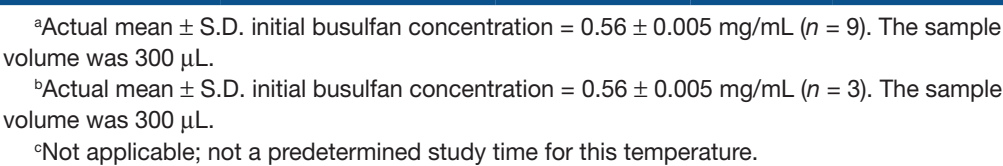 } \\
\hline
\end{tabular}

but the precipitate took the form of a granular film on the bags' surface. Interestingly, some bags showed precipitate formation after only 15 hours, while others showed no precipitate after 100 hours. For each bag, the appearance of precipitate was correlated with a strong diminution of busulfan concentration found by UHPLC-MS (Figure 1). In the worst case, the 100$\mathrm{mL}$ infusion bags remained stable at $2-8{ }^{\circ} \mathrm{C}$ for 12 hours (Table 4 ), consistent with the manufacturer's storage recommendations. The same vari- ability in precipitate formation was observed for the 500-mL infusion bags (Figure 2). However, the stability time was shorter than expected (9 hours instead of 12 hours) (Table 5).

The results of this study confirmed that polypropylene syringes offered the best stability times, regardless of the storage temperature. However, the stability of busulfan at $2-8{ }^{\circ} \mathrm{C}$ in these syringes was considerably increased compared with the manufacturer's recommendations. As discussed in other studies, there are 2 independent 
Table 4. Stability of Busulfan $0.54 \mathrm{mg} / \mathrm{mL}$ in $0.9 \%$ Sodium Chloride Injection Stored in 100-mL Polypropylene Infusion Bags

\begin{tabular}{|c|c|c|c|c|}
\hline \multirow[b]{3}{*}{ Study Time (hr) } & \multicolumn{4}{|c|}{ Mean \pm S.D. $\%$ Initial Busulfan Conc. Remaining at Indicated Storage Temperature } \\
\hline & \multicolumn{3}{|c|}{$2-8^{\circ} \mathrm{Ca}^{\mathrm{a}}$} & \multirow[b]{2}{*}{$23-27^{\circ} \mathrm{C}^{b}$} \\
\hline & Lot $\mathbf{A}$ & Lot B & Lot C & \\
\hline 3 & $99.59 \pm 1.38$ & $99.79 \pm 1.70$ & $98.58 \pm 1.08$ & $96.03 \pm 0.23$ \\
\hline 6 & $95.28 \pm 1.75$ & $96.04 \pm 1.03$ & $95.89 \pm 1.30$ & $90.78 \pm 1.05$ \\
\hline 9 & $97.04 \pm 1.56$ & $96.99 \pm 0.09$ & $97.49 \pm 1.35$ & $90.01 \pm 0.53$ \\
\hline 12 & $96.75 \pm 1.89$ & $98.22 \pm 1.19$ & $98.10 \pm 2.73$ & $88.55 \pm 1.32$ \\
\hline 15 & $99.43 \pm 2.15$ & $99.42 \pm 0.93$ & $95.90 \pm 6.19$ & $87.59 \pm 0.38$ \\
\hline 19 & $96.61 \pm 1.48$ & $97.30 \pm 0.62$ & $75.02 \pm 44.1$ & $84.20 \pm 0.61$ \\
\hline 23 & $97.07 \pm 1.18$ & $97.23 \pm 0.59$ & $56.96 \pm 67.5$ & $79.36 \pm 0.57$ \\
\hline 28 & $94.04 \pm 0.63$ & $87.19 \pm 12.1$ & $43.22 \pm 104$ & $73.79 \pm 1.57$ \\
\hline 31 & $95.40 \pm 2.23$ & $79.83 \pm 33.5$ & $44.49 \pm 84.7$ & $74.12 \pm 4.55$ \\
\hline 33 & $98.71 \pm 2.26$ & $72.26 \pm 51.9$ & $37.93 \pm 124$ & $N A^{c}$ \\
\hline 100 & $86.94 \pm 1.70$ & $61.47 \pm 37.4$ & $34.06 \pm 66.4$ & NA \\
\hline
\end{tabular}

Table 5. Stability of Busulfan $0.54 \mathrm{mg} / \mathrm{mL}$ in $0.9 \%$ Sodium Chloride Injection Stored in 500-mL Polypropylene Infusion Bags

\begin{tabular}{|c|c|c|}
\hline \multirow[b]{2}{*}{ Study Time, hr } & \multicolumn{2}{|c|}{$\begin{array}{c}\% \text { Initial Busulfan Conc. } \\
\text { Remaining at Indicated Storage } \\
\text { Temperature }\end{array}$} \\
\hline & $2-8^{\circ} \mathrm{C}^{\mathrm{a}}$ & $23-27^{\circ} C^{b}$ \\
\hline 3 & $N A^{c}$ & 98.41 \\
\hline 5 & $96.12 \pm 0.36$ & $91.25^{d}$ \\
\hline 9 & $92.63 \pm 1.08$ & 85.03 \\
\hline 13 & $87.89 \pm 10.8$ & 86.42 \\
\hline 16 & $80.27 \pm 15.3$ & 81.68 \\
\hline 19 & $71.19 \pm 26.0$ & 77.36 \\
\hline 22 & $53.02 \pm 30.5$ & 71.87 \\
\hline
\end{tabular}

aResults expressed as mean \pm S.D. $(n=3)$. Mean \pm S.D. initial busulfan concentration $=0.53$

$\pm 0.004 \mathrm{mg} / \mathrm{mL}(n=3)$. The sample volume was $500 \mu \mathrm{L}$.

bInitial busulfan concentration $=0.53 \mathrm{mg} / \mathrm{mL}(n=1)$. The sample volume was $500 \mu \mathrm{L}$.

'Not applicable; not a predetermined study time for this temperature.

${ }^{\mathrm{d}} \mathrm{A}$ systematic error (1.3\%) should be considered when examining results.

phenomena that explain busulfan degradation. At a high temperature, the main cause is hydrolysis; at a low temperature, the precipitation is the main source of product instability. Crystallization of a metastable solution is initiated by a nucleation process followed by crystal growth resulting from consecutive additions of molecules onto the nucleus. Both steps are influenced by numerous factors and are difficult to predict. Indeed, temperature, agitation, and interactions between product and container are known to influence the precipitation kinetics. ${ }^{26}$ Other potential variables that could affect busulfan degradation include the roughness of the container, surface area:volume ratio, and adsorption affinity of the drug molecule to the surface. These factors might explain the variability observed between the container types. They could also explain the variability observed within the same container type, such as with the 100 -mL bags.

Karstens and Kramer $^{13}$ tried to extrapolate the influence of temperature on busulfan crystallization. They found that an intermediate storage temperature of $14{ }^{\circ} \mathrm{C}$ could extend the shelf life of diluted busulfan solutions. This result was not confirmed by Houot et al. ${ }^{14}$ An intermediate temperature was excluded from our study because it would have created additional storage problems, as climatic chambers would have been necessary in all care units that use busulfan.

Published data and the results of the current study suggest that the physical stability of diluted busulfan solutions is very labile and strongly dependent on container type. Indeed, 
Figure 1. Stability of busulfan at $0.54 \mathrm{mg} / \mathrm{mL}$ in $0.9 \%$ sodium chloride injection at $2-8{ }^{\circ} \mathrm{C}$ and stored in $3100-\mathrm{mL}$ infusion bags for lot $\mathrm{C}$. Each line represents 1 of the 3 bags. The red dashed lines correspond to the higher and lower acceptance limits.

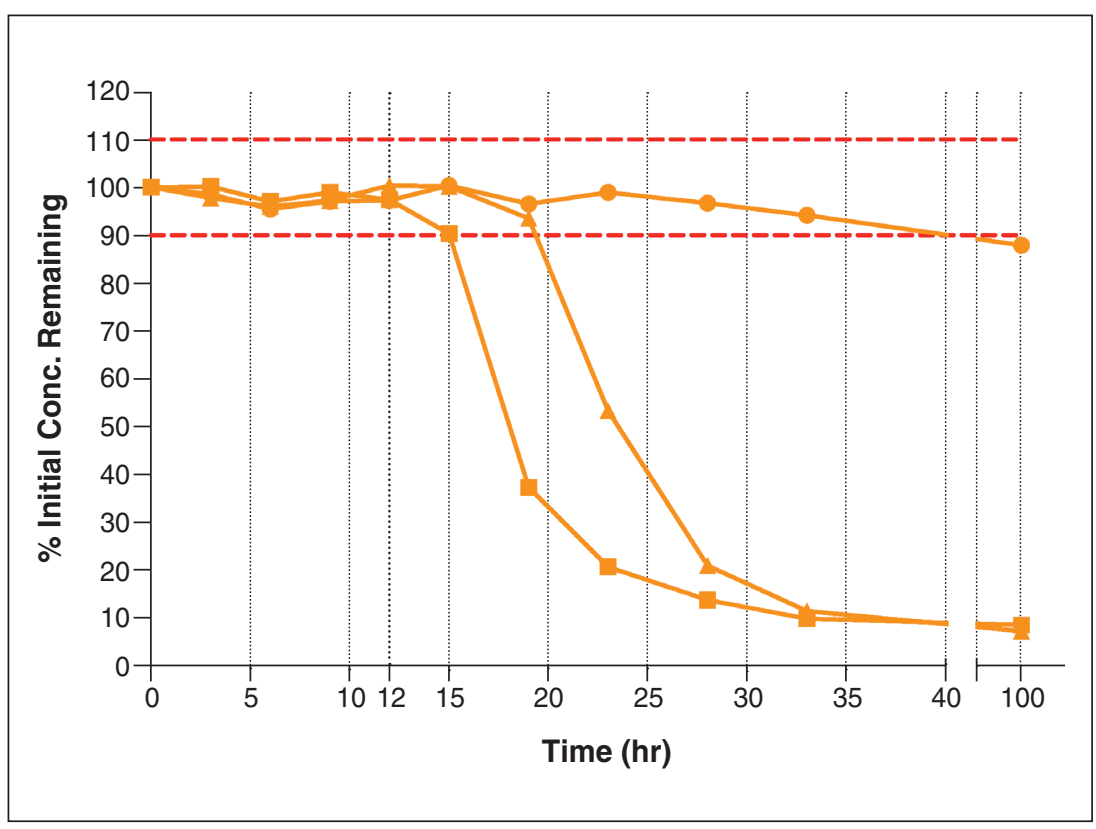

Figure 2. Stability of busulfan at $0.54 \mathrm{mg} / \mathrm{mL}$ in $0.9 \%$ sodium chloride injection at $2-8{ }^{\circ} \mathrm{C}$ and stored in $500-\mathrm{mL}$ infusion bags for lot $\mathrm{A}$ (blue dots), B (orange triangles), and $\mathrm{C}$ (green squares). The red dashed lines correspond to the higher and lower acceptance limits.

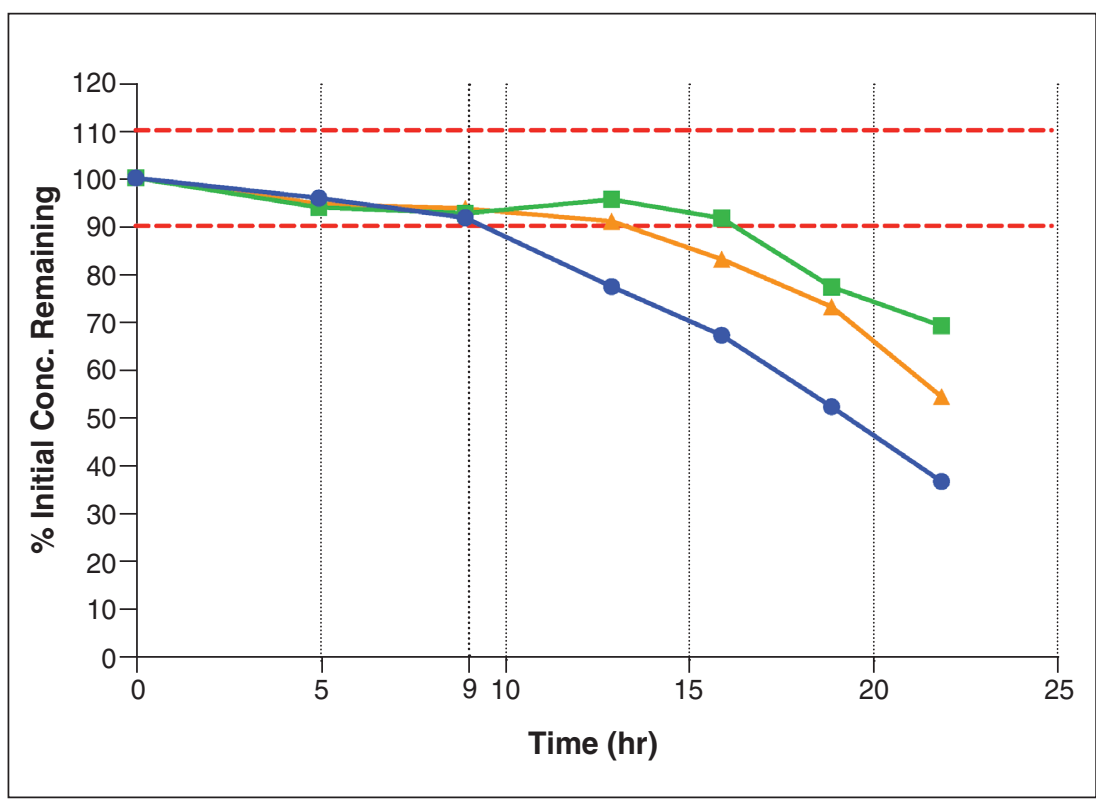

of the containers tested in this study, syringes offered the best stability regardless of the storage temperature. Moreover, the solutions remained stable for a longer period of time when they were stored in refrigerated conditions. Because high variability was observed in the precipitation time and rate of busulfan, inspection of busulfan containers before transport to care units and before administration to patients is strongly recommended.

The extended shelf life of busulfan infusion stored in syringes allowed for better organization of the chemotherapy preparation unit by reducing busulfan production to once daily. This allowed the 4 doses of busulfan required for a patient each day to be prepared at the same time and sent to care units in advance.

\section{Conclusion}

Busulfan 0.54-mg/mL solution in $0.9 \%$ sodium chloride injection was physically and chemically stable for 30 hours when stored in $50-\mathrm{mL}$ polypropylene syringes at $2-8{ }^{\circ} \mathrm{C}$ and protected from light.

\section{Disclosures}

The authors have declared no potential conflicts of interest.

${ }^{a}$ Busulfan, analytic standard for drug analysis, Sigma-Aldrich, St. Louis, MO, lot BCBN8120V.

${ }^{\mathrm{b}}\left[{ }^{2} \mathrm{H}_{8}\right]$-busulfan, Alsachim, Strasbourg, France, batch CM-ALS-11-167-B1.

'Busilvex, busulfan $6 \mathrm{mg} / \mathrm{mL}$ (10 $\mathrm{mL}$ ), Pierre Fabre Pharma SA, Allschwill, Switzerland, lots AD5362B, AD9058B_1, and AD7703D_1 (called lots A, B, and C, respectively, in this study).

${ }^{\mathrm{d} B D}$ Luer-Lok Plastipak syringes, 50 mL, Becton Dickinson, Franklin Lakes, NJ, ref. no. 300865, lot 1505235.

'Tamper-evident cap, B. Braun Medical, Bethlehem, PA, ref. no. 418004 , lot 61458781.

fSodium chloride $0.9 \%$ Bioren 500and $100-\mathrm{mL}$ bags, Sintetica, Mendrisio, Switzerland, ref. no. 420028, lot 15112269B (for 500-mL bags) and ref. no. 420025, lot 15092230A (for 100-mL bags).

'Type 1 ultrapure water, Milli-Q purification system, Merck-Millipore, Darmstadt, Germany. 
${ }^{\mathrm{h}}$ Acetonitrile hypergrade for LC-MS,

Merck, Darmstadt, Germany, lot

I784629529.

${ }^{i}$ Formic acid for mass spectrometry, 98\%, Sigma-Aldrich, lot BCBP4740V.

'Ammonium formate for mass

spectrometry, $>99.0 \%$, Sigma-Aldrich, lot BCBP6806V.

${ }^{k}$ Aqua ad iniect. Ph. Eur. steril, Laboratorium Dr. G Bichsel AG, Unterseen, Switzerland, lot 1000247.

'Sodium hydroxide solution, $1 \mathrm{~mol} / \mathrm{L}$, Merck, lot HC681199637.

mHydrochloric acid, 1 mol/L, Merck, lot HC253654.

${ }^{n} H y d r o g e n$ peroxide $30 \%$ for analysis, Merck, lot K46362809512.

${ }^{\circ} \mathrm{N}, \mathrm{N}$-dimethylacetamide anhydrous, 99.8\%, Sigma-Aldrich, lot STBF4798V.

pPolyethylene glycol, Macrogol 400

$\mathrm{Ph}$. Eur., Hanseler, Herisau, Switzerland, lot 2015.07.0183.

${ }^{\mathrm{q} S}$ Sogevac SV 40 BI, Leybold, Cologne, Germany.

rWaters Aquity UPLC H-Class Sample manager-FTN, Waters, Milford, MA.

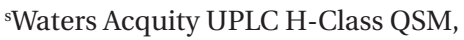
Waters.

'Waters Acquity UPLC BEH Shield RP18, $2.1 \times 50 \mathrm{~mm}, 1.7-\mu \mathrm{m}$ particle size, Waters, lot 01503326015908

"Waters Acquity UPLC BEH Shield RP18 $2.1 \times 5$ mm, 1.7- $\mu \mathrm{m}$ VanGuard PreColumn, Waters, lot 0161352101.

vWaters Acquity CH-A column heater, Waters.

wWaters TQD, Waters.

'Omnifix 10 mL, B. Braun, Melsungen, Germany, lot 15L19C8.

yBD Microbalance 3 18G needle, Becton Dickinson, ref. no. 304622, lot 150805.

${ }^{2}$ BD 1-mL Luer-Lok Tip syringe, Becton Dickinson, ref. no. 309628, lot 5201845CAV08.

aa Neolus $22 \mathrm{G}$ hypodermic needle, Terumo, Tokyo, Japan, ref. no. NN-2232S, lot 1401005 .

\section{References}

1. Hassan M. The role of busulfan in bone marrow transplantation. Med Oncol. 1999; 16:166-76.

2. Haddow A, Timmis GM. Myleran in chronic myeloid leukaemia; chemical constitution and biological action. Lancet. 1953; 261:207-8.

3. Slattery JT, Clift RA, Buckner CD et al. Marrow transplantation for chronic myeloid leukemia: the influence of plasma busulfan levels on the outcome of transplantation. Blood. 1997; 89:3055-60.

4. Tabak A, Hoffer E, Rowe JM, Krivoy N. Monitoring of busulfan area under the curve: estimation by a single measurement. Ther Drug Monit. 2001; 23:526-8.

5. Scott LJ, Hoy SM, Lyseng-Williamson KA. Intravenous busulfan: a guide to its use as conditioning treatment before transplantation of haematopoietic progenitor cells. Clin Drug Investig. 2012; 32:641-8.

6. Food and Drug Administration. Busulfex approval label. www.accessdata.fda.gov/drugsatfda_docs/ label/1999/20954lbl.pdf (accessed 2016 May 2).

7. Bornhauser M, Storer B, Slattery JT et al. Conditioning with fludarabine and targeted busulfan for transplantation of allogeneic hematopoietic stem cells. Blood. 2003; 102:820-6.

8. Przepiorka D, Ippoliti C, Giralt S et al. A phase I-II study of high-dose thiotepa, busulfan and cyclophosphamide as a preparative regimen for allogeneic marrow transplantation. Bone Marrow Transplant. 1994; 14:449-53.

9. European Medicines Agency. Busilvex: summary of product characteristics. www.ema.europa.eu/docs/en_GB/ document_library/EPAR_-_Product_Information/human/000472/ WC500052066.pdf (accessed 2016 May 9).

10. Feit PW, Rastrup-Andersen N. 4-Methanesulfonyloxybutanol: hydrolysis of busulfan. J Pharm Sci. 1973; 62:1007-8.

11. Hassan M, Ehrsson H. Degradation of busulfan in aqueous-solution. J Pharm Biomed Anal. 1986; 4:95101.

12. Xu QA, Zhang YP, Trissel LA, Martinez JF. Stability of busulfan injection admixtures in 5\% dextrose injection and $0.9 \%$ sodium chloride injection. $J$ Oncol Pharm Pract. 1996; 2:101-5.

13. Karstens A, Kramer I. Chemical and physical stability of diluted busulfan infusion solutions. Eur J Hosp Pharm Sci Pract. 2007; 13:40-7.

14. Houot M, Poinsignon V, Mercier L et al. Physico-chemical stability of busulfan in injectable solutions in various administration packages. Drugs $R D$. 2013; 13:87-94

15. Moon SY, Lim MK, Hong S et al. Quantification of human plasma-busulfan concentration by liquid chromatography-tandem mass spectrometry. Ann Lab Med. 2013; 34:7-14
16. Ansari M, Uppugunduri CR, Déglon J et al. A simplified method for busulfan monitoring using dried blood spot in combination with liquid chromatography/tandem mass spectrometry. Rapid Commun Mass Spectrom. 2012; 26:1437-46.

17. Desire S, Mohanan EP, George B et al. A rapid and sensitive liquid chromatography-tandem mass spectrometry method for the quantitation of busulfan levels in plasma and application for routine therapeutic monitoring in haematopoietic stem cell transplantation. Indian J Med Res. 2013; 137:777-84.

18. Dos Reis EO, Vianna-Jorge R, SuarezKurtz G et al. Development of a rapid and specific assay for detection of busulfan in human plasma by highperformance liquid chromatography/ electrospray ionization tandem mass spectrometry. Rapid Commun Mass Spectrom. 2005; 19:1666-74.

19. French D, Sujishi KK, Long-Boyle JR, Ritchie JC. Development and validation of a liquid chromatographytandem mass spectrometry assay to quantify plasma busulfan. Ther Drug Monit. 2014; 36:169-74.

20. Connor TH, McDiarmid MA. Preventing occupational exposures to antineoplastic drugs in health care settings. CA Cancer J Clin. 2006; 56:354-65.

21. Hubert P, Nguyen-Huu JJ, Boulanger B et al. Harmonization of strategies for the validation of quantitative analytical procedures. A SFSTP proposal - part I. $J$ Pharm Biomed Anal. 2004; 36:579-86.

22. Hubert P, Nguyen-Huu JJ, Boulanger B et al. Harmonization of strategies for the validation of quantitative analytical procedures. A SFSTP proposal part II. J Pharm Biomed Anal. 2007; 45:70-81.

23. Hubert P, Nguyen-Huu JJ, Boulanger B et al. Harmonization of strategies for the validation of quantitative analytical procedures. A SFSTP proposal part III. J Pharm Biomed Anal. 2007; 45:82-96.

24. Sautou V, Brossard D, Chedru-Legros $\mathrm{V}$ et al. Guide méthodologique des études de stabilité des préparations. www.gerpac.eu/IMG/pdf/guide_de_ stabilite_vf_avril2013.pdf (accessed 2017 May 25)

25. Weaver R, Riley RJ. Identification and reduction of ion suppression effects on pharmacokinetic parameters by polyethylene glycol 400. Rapid Commun Mass Spectrom. 2006; 20:2559-64.

26. Mullin JW. Crystallization, 4th ed. Oxford:Butterworth-Heinemann; 2001:181-3. 